\title{
HEALTHCARE POLICY OF GEORGIA AND ACTIVE ENGAGEMENT OF SOCIETY
}

\author{
NINO MIKIASHVILI \\ Doctor of Economics, Associate Professor, \\ Ivane Javakhishvili Tbilisi State University, \\ Faculty of Economics and Business \\ Tbilisi, Georgia \\ nino.mikiashvili@tsu.ge
}

\section{TINATIN TARASHVILI}

Unite for Healthcare and Education,

\section{Master of Business}

u4hce.org@gmail.com

Abstract. Purpose. The research project "Active Engagement of society in Health care policy" studies hospitals, medical personnel (doctors and nurses) and patients as the main components of Healthcare System in Georgia, targeting two regions Tbilisi and Kutaisi. The initial aim of this research project was to answer the following questions: what is the disposition, viewpoint of the hospital management representatives, medical personnel and patients towards the healthcare policy? What is the level of quality of health services for patients? What is the level of awareness? How actively are different parties involved in the health care system?

Project description. The health care policy of Georgia must respond to contemporary challenges and enhance the wellbeing of the public. Given the relevance of the issue, it is important to study and analyze the public awareness towards the development of a rational health care policy that is focused on delivering competitive medical services. The main novelty of the study is to involve three different stakeholders: hospital management, medical personnel and patients in the research process. Each group has a specific interest and attitude, which in turn determines the degree and extent of their engagement, but each of them proves the need for changes.

The study revealed that patients as the final recipients of medical services are informed about health funding higher than average based on data analysis from both clinics from Tbilisi and Kutaisi (50\% of respondents are fully informed, $40 \%$ partially informed, and $10 \%$ are uninformed). $80 \%$ of patients receive information about medical funding directly from their medical staff at a particular place, where they receive health care service. $87.5 \%$ of hospital managers are actively involved in the process of change and collaborate with government health legislation. When it comes to both capital and on-going costs, $87.5 \%$ of the funding is spent by mobilizing the internal funds of the clinics, while only $12 \%$ comes from complex financing. $83.3 \%$ of medical personnel believe that they are involved in the process of clinic's management and thus in healthcare policy. They generally see the changes to be implemented with the following justifications: improvement of material-technical base of hospitals $8.3 \%$, organizational structure $16.7 \%$, legislative $33.3 \%$, Insurance package optimization for patients $16.7 \%$. This mandates the need for improvement of legislative and insurance reforms.

Previous studies of Georgiass health care system, consistently demonstrated the satisfaction of beneficiaries of a universal health care program with medical services. This data strongly supports the high level of satisfaction of patients with the quality of received medical services in this study. The data analysis showed that patients average satisfaction with the quality of medical services is 4.8 out of 5 for both cities. Despite the increasing satisfaction with quality of medical service for patients, is a subjective process, increasing the risks of medical errors in managing the treatment process. It is imperative to assess the medical risk for both the administration and medical staff. It depends on the prestige of the medical institution and staff and the continued smooth operation of the medical service. Medical risk is directly relevant to patients, so it is advisable to evaluate the impact of various factors on occupational (medical) risk management $(\mathrm{R})$ using multiple regression analyzes within the current data. Exogenous factors are as follows: q1 Demand for the medical profession, q2 Competition in the professional market, q3 Satisfaction with organizational culture and management, q4 Feedback. In this case, the correlation coefficient is 0,876 , the coefficient of determination is 0.767 , the coefficient of correction -0.612 and the standard deviation is 0.420 . According to the $F$ test, the equation was found to be significant at the $5 \%$ significance level.

The equation: $R=-2.517+0.195 q 1+0.575 q 2+1.195 q 3-1.080 q 4$

And the standardized equation is: $\mathrm{W}=0.117 \mathrm{z} 1+0.375 z 2+0.717 z 3-0.483 z 4$

Factors 2 and 3 in the equation are statistically significant. The signs of regression equation coefficients reflect the 
subjective attitude towards job risk protection that managers should consider - a competitive environment not generally, but fears of losing particular jobs due to unhealthy approaches, stress on staff, aggravates staffing, or detention or retention conditions.

A successful health care setting must provide improved quality care at lower costs, easily available for patients and developing official feedback system through different settings.

Methods. The design of this study was a direct interview method retrospective case control study. Participants were two hospitals in different cities (regions) of Georgia, Tbilisi and Kutaisi. One of them belongs to "Evex medical corporation" and the second one to the network of «Geo Hospitals». Three different types of questionnaires were used for each group (1. For doctors and nurses; 2 . For management representatives of the hospital; 3. For patients). Total 40 questions. The most of the conclusions were statistically significant and thus their generalization was possible. The age range of the respondents was $18-70$ years; $65 \%$ of the respondents were women. Considering the significant difference of each group three different interview questionnaires were used.

Results. The results showed that the part of the society, namely, patients based on received data analysis are generally informed more than average level 0.681 (standard deviation). 50\% of the patients say to be completely informed, only $10 \%$ of them say that they are not at all aware and $40 \%$ say to be moderately aware about the ongoing processes in Healthcare policy in Georgia. $80 \%$ of the patients are informed about the health service financing issues from medical personnel at the place of specific medical services. $87.5 \%$ of the management representatives from both regions are actively involved in healthcare policy. $88 \%$ of total participants of our project expressed their opinion and only $12 \%$ avoided commenting towards the desirable changes.

For the evaluation of hospitals' management were asked whether the management of the clinic is actively involved in health policy, or if the clinicss leadership is trying to change something «contrary to the law», $20 \%$ of respondents are trying to be actively involved in health care legislation processes. They are resolving the issue legally, and a similar percentage of respondents are trying to solve the problem with the resources within the clinic.

The difference in the number of patients about the earlier awareness regarding the quality of medical services available in the hospitals is not significant in both cities. The survey shows that most patients at both clinics have prior knowledge of the quality of medical services available at the clinic as to treatment expectation.

Conclusions. A large concern regarding the Georgian health care policy amendments are strongly related with general public health. The results of this study demonstrate a potential positive willingness of three different groups to cooperate and being involved in healthcare system decision making process. This observation in addition adds strength to the continued endorsement of medical professionals that their opinion to be considered while healthcare delivery throughout the country. The findings highlight that $88 \%$ of the randomly selected respondents are open for interaction, can express their opinion regarding health care policy, insurance policy; evaluate the quality of health care and financial issues regarding health service and medication, the level of awareness and satisfaction with quality of health services. The study showed that the health care system of Georgia is developing in the directions so that no significant shortcomings are observed. It is noteworthy that reservations are very important for the active involvement of the public. Additional studies are needed to deduce an exact cause and effect relationship between public awareness and healthcare policy management.

KEYWORDS: MANAGEMENT, HEALTHCARE POLICY, ECONOMICS OF HEALTHCARE, INSURANCE POLICY, PUBLIC AWARENESS.

For citation: Mikiashvili, N., \& Tarashvili, T., (2020). Healthcare Policy and Active Engagement of Society. Globalization and Business, 10. 185-191. https://doi.org/10.35945/gb.2020.10.023

\section{INTRODUCTION}

Georgiars healthcare policy has been an interest of many researchers. Since 2003 many changes towards reformation of the health care policy and social security system have been done. It is noteworthy that there is no another country, except Georgia, where so many quick reforms are undertaken; There are vast majority of reforms undertaken by the government (Verulava, 2016).

It is a well-known fact, that since 2013 the universal health care state program has been launched in Georgia, the purpose of which is to provide financial support and access to medical services for Georgian citizens, who do not have any health insurance coverage. The government will to take certain obligations to reform the healthcare system is very important, which has a significant impact on each person. Although government spending significantly increases in health care, it is still quite small in percentage figures $-6,7 \%$ in $2014,8.0 \%$ and $8.1 \%$ in 2015 and 2016, almost twice as low as other countries Similar indicators (World Health Organization LG Health-Care 2017). In general, it is quite difficult to create economically effective governing healthcare system by the Government.

Government spending on health care depends on a number of factors, such as: community values, priorities, political commitment, economic sustainability and the amount of government budget. Studies show that more Government spending for Healthcare means more 
affordability for Health services, and as a result this indicates the increase of general indicator of Health of the country's population (Getzen, 2012).

In terms of reforms, it is worth mentioning the changes in terms of administration - involvement of the Social Service Agency in the healthcare system. It is known that in the beginning of the healthcare system reforms, insurance companies, as intermediate administrative entities were between the state and the medical centers, and they used to earn profound profits. As a result of the reforms, these administrative expenditures go to the medical service centers instead of the insurance companies. Financial expenditure may have been increased even more than a year ago, but we will get a real picture while summarizing the results - much more people receive medical care than before. Currently the processes are controlled by the Social Service Agency. They have powerful tools for administration. The Agency has the right to verify any facts and it sends all suspicious cases in terms of medical breach to the regulatory agency for further reaction (Cheishvili 2016).

It is important to note that some parts of the population have been critical of the state health care costs in recent years, since they believe that this is a heavy burden for the poor state budget (Latsabidze, 2015). In other words, this social direction of the state budget reduces the main expenditures of the government, but it hinders the countryss economic development.

Among the studies targeting the Georgiass healthcare system, it is interesting to mention the study examining the level of satisfaction of population who receive benefits from the state healthcare program in Georgia in 2016. It is said that «General satisfaction for beneficiaries is very high while receiving medical services using the universal health care program» (Verulava and Beliskiria, 2016). Involvement in this program has improved their physical and financial access to medical services, and they are even more frequently using medical services than before launching this program. "The majority of respondents generally are aware about the state healthcare program. However, almost half of the respondents still fail to find out to whom should they address in case of any problem occurrence and how to get medical service "(Verulava and Bulletin, 2016).

The inspiration for this study was coming from the circumstances, to enhance a health and social security system that would help to maximize the overall wellbeing of the society, and it would be oriented to deliver competitive health care based on social justice and human principles. The main novelty of the research project could be the involvement of three groups, related directly with the health care system. Each group has a particular interest and attitude, which in turn contributes to the quality and scope of their engagement.

Public involvement in the health care system, like hospital administrative representatives, doctors and nurses and patients are different due to their interests, but each party confirms the need for changes. Considering the statistical and analytical conclusions and results obtained within the project will be useful for the clinics' administrative purposes and also for the persons interested with health care management issues. Confrontation of results obtained in a small selection will be of interest to other clinical and regional data, for which a large-scale survey should be carried out.

\section{Methodology and Data Collection}

Data were collected by face to face interview method, using three different type of questionnaires for each group. Total 41 questions were used (see appendix). Medical staff was interviewed with 13 questions, administration 14, and patients with 11.8 participants were the representatives of hospital management, 12 of them were doctors and nurses and 20 patients. Overall 40 respondents representing two different regions -20 from Tbilisi and 20 from Kutaisi. From 20 patients 4 of them were the patients who had already left the hospital and have had completely received medical service from the clinic. Three different types of questionnaires were used for each group (1. For doctors and nurses; 2 . For management representatives of the hospital; 3 . For patients). We have used 3 additional questions for general filtration, in terms of statistical analysis of data. 40 respondents are the total discretion of the research. The age range is $18-70$ years; $65 \%$ of respondents are women; Location - two cities, Tbilisi and Kutaisi. SPSS program was used for statistical analyses.

\section{RESULTS}

\section{Assessment of clinic management}

The question was whether the clinic management is actively involved in health care policy, or if the management of the clinic tries to change something «in case of contradiction with the law, " (if any issue is incompatible with the legislative base) the question was given to 8 respondents. $50 \%$ of respondents from the given group, are trying to be actively involved in health care policy issues (Question 16). They try to settle the issue in the legislative form.

While supervising the hospitals and managing financial, infrastructural and technical issues, $37.5 \%$ of the administration is trying to solve the problems by using internal financial resources of clinic. However, while financing the organization, $87.5 \%$ comes on internal financial resources within the clinic and only $12.5 \%$ comes on the complex financing, including budgetary funds (according to questions 17 and 18).

In order to evaluate how medical personnel is involved in management and development of the hospital itself, medical staff as the most important part of the society, we have had 12 respondents (4th question). 83,3\% (valid 90.9\%) thinks that they are actively involved. However, 8,3\% (9,1\%) does not have the same feeling.

The finding how medical personnel see what type of needs to be met and changes to be made within the organization and also in the health care processes in the country (12th question) we have received the following results. $8,3 \%(10 \%)$ of respondents are reporting the improvement of ethics; $16.7 \%$ (20\%) report structural changes and majority $33,3 \%$ (40\%) of them report legislative 
amendments and optimization of insurance package 16, 7\% (20\%).

There is an interesting question how management is open for personnel's professional feedback and their openness at work (23th question). The findings show that $62.5 \%$ of the administration representatives giving average evaluation to colleague's feedback (highest ranking from 10 they choose 5); however, $37.5 \%$ of management representatives are most welcoming to receive feedback from stuff. (7 from 10).

Regarding the level of satisfaction of the staff with the governance of each clinic (3rd question) and the protection of professional risks for medical professionals (7th question) in both cities we have received following findings. $16,7 \%$ of stuff satisfaction is average, while $83,3 \%$ of them show higher level of satisfaction with organizational governance. $8,3 \%$ of stuff indicate to be partially protected from the professional risks, while $41.7 \%$ of them express average level of safety and $50 \%$ indicate to be fully protected from medical professional risks. However, medical personnel feel to be more protected from their clinic's itself, than from the state. Differences between the regions in this regard are statistically insignificant.

\section{Assessment of Financing}

Table 1 shows financial resources (17th and 18th questions) for the hospitals. As mentioned earlier, $87,5 \%$ comes on internal financial resources of hospitals (selfsustainable) to meet organizational expenses such as capital expenditure of organization, ongoing expenses, purchase of medical equipment for the clinic, employees' honorarium. Only $12.5 \%$ comes on other comprehensive financing sources, such as grant $(9 \%)$ or specific sponsor.

Data analyses for the financial compensation assessment for the medical personnel according to their remuneration or honorarium they receive for the fulfilled work $50 \%$ of stuff evaluates neutrally, while $33.3 \%$ of stuff shows the full compliance and only $16.7 \%$ of them shows partial satisfaction with received honorarium in both regions.

\section{Analysis of satisfaction with the quality of medical service, paid prices for medications and medical services}

The level of satisfaction with the quality of medical service is evaluated according to 4 gradations: very satisfied, satisfied, complaining and very unhappy. With 5 we noted very satisfied, with 4 - satisfied, and with 3 and 2 - respectively complaining and very unhappy. Data analysis showed that the average level of satisfaction with regard to the quality of medical care is 4,8 points out of 5 for patients for both regions. There is no statistically significant difference between regions with $5 \%$ of the level of significance. It is 4,9 in Tbilisi and 4,7 points in Kutaisi.

The level of satisfaction with quality of health care was also evaluated by the doctors and nurses. Analyses show 4,2 points out of 5 for both regions. As for the difference between regions average level of satisfaction with quality of health care it is 4.17 in Tbilisi and 4.25 in Kutaisi. However, this distinction is not statistically significant between Tbilisi and Kutaisi (with $5 \%$ of the level of significance).

This difference is statistically important with $1 \%$ level of significance while medical personnel and patients are evaluating the quality of healthcare services in Georgia, which is due to two reasons: patients are more honest with doctors, or doctors themselves are less satisfied with the existing system and this impact is reflected over the received information for research.

Patients evaluate the financing of medical services as follows: The question was how much the sum paid by them meet the quality of the medical care they receive. Data show an average of 4,6 points for both regions. As mentioned earlier with 5 we noted very satisfied as in the previous case. There is a slight difference between two regions. Data analysis show it is 4,62 in Tbilisi and 4,57 in Kutaisi.

The substantial difference between the cost of medicines and medical services and the satisfaction of the medical quality did not occur, which is due to the age category of respondents, the majority belonged to the pension age category.

Conducted regression analysis in order to examine the strength of relationships between the medical personnelss self-realization level, the financial benefits they receive and the quality of the medical service performed by them; However, given the lack of significance influence of these two above mentioned factors over the third one - the quality of medical service, the level of significance has not been confirmed.

\section{Assesment of Feedback system}

Representatives of medical staff from both regions in terms of giving and receiving feedback on a professional basis to clinic management - is evaluated by management as average of 5,75 points from highest 10 point. The feedback level is relatively high - 6.5 in Tbilisi.

Table 4 shows the evaluation of the feedback system

Table 1. Distribution of frequency sources of current financing

\begin{tabular}{|l|l|l|l|l|l|}
\hline \multicolumn{2}{|l|}{} & Frequency & Percent & Valid Percent & $\begin{array}{l}\text { Cumulative } \\
\text { Percent }\end{array}$ \\
\hline 2 clinic internal resources & 7 & 87.5 & 87.5 & 87.5 \\
\hline $\begin{array}{l}5 \text { complex financial } \\
\text { resources }\end{array}$ & 1 & 12.5 & 12.5 & 100.0 \\
\cline { 2 - 5 } & & 100.0 & 100.0 & \\
\hline
\end{tabular}


Table 2. Measuring the level of satisfaction and connection between two groups

\begin{tabular}{|l|c|c|}
\hline $\mathrm{N}$ & Medical Personnel & Patients \\
\hline $\begin{array}{l}\text { Average level of satisfaction with the } \\
\text { paid price for Healthcare services and } \\
\text { medication }\end{array}$ & N/A & 4.65 \\
\hline $\begin{array}{l}\text { Average level of satisfaction with the } \\
\text { quality of health services }\end{array}$ & 4.2 & 4.8 \\
\hline
\end{tabular}

within the clinic assessed by medical stuff.

The findings show that there is no official feedback system within the clinics, but there is verbal communication between patients and medical personnel. It is worth mentioning, how do patients assess medical personnel, most of them admit that they are «very good».

\section{Assessment of a level of awareness}

What is the level of awareness of society towards healthcare system, ongoing changes within it, funding and insurance issues?

The level of awareness in patients is evaluated by the opinion of 20 respondents, which is $50 \%$ of the survey participants. Collected information has focused to determine what was the level of their awareness and how many of them were informed earlier? Examining the level of awareness of patients in general, their rights and the current changes in the health care system is important and interesting.

\section{The level of awareness in patients}

The survey shows that most of the patients in both clinics have had information about the quality of medical services in each clinic. As for the expectation for treatment and the information they were holding regarding the level of medical service quality for both hospitals, the absolute majority were completely satisfied with the received quality of medical treatment. 10 points were recorded in this case from maximum 10.

Most of our respondents were belong to the category of pension receivers. For this category of people there are full financial packages from the state budget. Naturally, the state fully undertakes their financial coverage, that could be one of the important factors for patients being totally satisfied with the prices they pay for hospital services. To sum up 90\% (18

Table 3. Statistical description of the frequency of feedback according to medical personnel

\begin{tabular}{|l|l|l|l|}
\hline $\begin{array}{l}\text { Frequen } \\
\text { cy }\end{array}$ & Percent & $\begin{array}{l}\text { Valid } \\
\text { Percent }\end{array}$ & $\begin{array}{l}\text { Cumulativ } \\
\text { e Percent }\end{array}$ \\
\hline 10 & 83.3 & 90.9 & 90.9 \\
\hline 1 & 8.3 & 9.1 & 100.0 \\
\hline 11 & 91.7 & 100.0 & \\
\hline 1 & 8.3 & & \\
\hline 12 & 100.0 & & \\
\hline
\end{tabular}

out of 20) of the respondents (from patients) use universal healthcare program, while only $10 \%$ of them use private insurance packages. However, the main source of information for most of the patients regarding the compensation scheme for health services are the medical personnel from the clinics they receive treatment.

Conducted statistical analyses regarding the level of awareness about their rights and ongoing changes in healthcare revealed that $50 \%$ of the patients say to be completely informed, only $10 \%$ of them say that they are are not at all aware and $40 \%$ say to be moderately aware and receive information mainly from their medical staff.

Based on data analysis for both clinics, the mean level of awareness in patients is 0.675 . It is slightly above average. The level of full awareness is indicated with 1 , the average level of awareness with 0.5 , and the level not aware at all is indictaed with -0 point.

If the level of awareness in Tbilisi is indicated with 0 and the level of awareness for patients' from Kutaisi with 1 , conducted statistical regression shows that the level of awareness in Kutaisi is higher with $0.15 \%$ than in Tbilisi though there is $40 \%$ of probability that this data is the same, but randomly selected 10 patients from Kutaisi were better informed.

Is there any dependence between the level of awareness and the level of satisfaction with quality and financial arrangements of medical treatment? Conducted regression did not confirm this. Furthermore, conducted regression analysis shows that dependence among the level of service quality of medical service and the level of awareness is higher than the dependence among financial aspect and the level of awareness. However, there were several younger respondents among patients who were informed earlier and financially (partially) protected from private insurance companies. In addition, most of the patients have mentioned being 'unselfish', while assessing the personnel.

\section{Assessment of employees' personal self-realization and professional growth}

The quality of personal self-esteem assessed by the management, in other words, how people are realized at work, how much skilled and qualified a medical person is employed in each position is assessed with 6,62 points out of 10 for both regions. It is 6.5 in Tbilisi - and 6,75 in Kutaisi.

Frequency of honorarium payment is $60 \%$, comparing $77 \%$ of moral encouragement to increasing motivation of employees. Promotion for professional growth and capacity building development, is highly encouraged in both regions, 
Table 4. Frequency of medical staff's opinion regarding desirable amendments

\begin{tabular}{|l|l|l|l|l|l|}
\hline \multicolumn{2}{|c|}{} & Frequency & Percent & Valid Percent & $\begin{array}{l}\text { Cumulative } \\
\text { Percent }\end{array}$ \\
\hline \multirow{5}{*}{ Valid } & $\begin{array}{l}\text { 1 Development of material- } \\
\text { technical base }\end{array}$ & 1 & 8.3 & 10.0 & 10.0 \\
\cline { 2 - 6 } & 2 Ethical changes & 1 & 8.3 & 10.0 & 20.0 \\
\cline { 2 - 6 } & 3 Structural changes & 2 & 16.7 & 20.0 & 40.0 \\
\cline { 2 - 6 } & 4 Legislative & 4 & 33.3 & 40.0 & 80.0 \\
\cline { 2 - 6 } & $\begin{array}{l}\text { 5 Optimization of Insurance } \\
\text { packages }\end{array}$ & 2 & 16.7 & 20.0 & 100.0 \\
\cline { 2 - 6 } & Total & 10 & 83.3 & 100.0 & \\
\hline Missing & 999 & 2 & 16.7 & & \\
\hline Total & 12 & 100.0 & & \\
\hline
\end{tabular}

although participation in international forums is not much and it only occurs with the frequency $3 \%$.

There is a positive attitude towards young people to help them develop their professional skills, while accepting the students and offering internships within the clinics.

Table 8 displays the results what is the opinion of medical personnel towards organizational and country's legislative direction and what type of changes should be made. Results show that $40 \%$ of valid percent share comes on legislative amendments out of $100 \%$, comparing with $10 \%$ of ethical and material-technical changes within the organization.

Survey results show that there is a shortage of some professional staff. $62.5 \%$ of respondents (5 out of 8 ) specify the staff shortage, namely, the lack of reanimathologist and anesthesiologist, mid level practitioners. In the list there are of narrow specialists, urgent medical emergency doctors and medical equipment engineers. However, only a fifth of management representatives believe that there are no shortage of specialists in the market.

\section{Assessment of professional (medical) risk protection of employees}

Table 9,10,11 displays statistics of Plural Regression Coefficients assessing how medical personnel is protected from professional risk. They use individual insurance packages from private insurance companies, but the staff feel more protected from clinic's side rather than the state. An average point for both regions is 7,25 oout of 10 , while it is 8,5 in Tbilisi, and 6.0 in Kutaisi, according to the management estimates. How do the doctors themselves evaluate it? We have the following picture: 8,33 average assessment in both regions, 8,5 in Tbilisi and 8,1 in Kutaisi.

\section{Prohibiting factors, barriers and challenges}

The frequency of financial and human resources as most precipitating (prohibiting) factors takes 33\% each and information barriers takes $9 \%$ while assessing the most common hindering factors for organizational development by management side.

Data analyses while assessing challenges by patience towards medical personal and vice versa, show that patients are completely satisfied and grateful while assessing the medical staff. However, some representatives of medical personnel approximately one third of them, mentions lack of access to medications for patients (in particular due to financial resources) and also the peculiarities of personal factors, such as the temper and suicide attempts with the frequency of $25 \%$.

\section{Reccommendations}

Establishment of the feedback system (platform) for the assessment of medical service quality for clinics, where patients will be able to evaluate the level of service and express their opinion. This information will help each clinic to analyze situation regarding the medical service and treatment they provide and get information regarding the patients' satisfaction or problems seen by patients.

Clinics should have freedom of choice while selecting insurance provides.

\section{ANOVA $^{\mathrm{a}}$}

Dependent Variable: q7 Protection from professional (medical) risks

Table 5. Dispersion analysis of multiple regression

\begin{tabular}{|c|c|c|c|c|c|}
\hline Model & $\begin{array}{l}\text { Sum of } \\
\text { Squares }\end{array}$ & Df & Mean Square & $\mathrm{F}$ & Sig. \\
\hline Regression & 3.488 & 4 & $\begin{array}{r}.87 \\
2\end{array}$ & 4.948 & .042 \\
\hline Residual & 1.057 & 6 & $\begin{array}{r}.17 \\
6\end{array}$ & & \\
\hline Total & 4.545 & 10 & & & \\
\hline
\end{tabular}


Coefficients $^{\mathrm{a}}$

Dependent Variable: q7 Protection from professional (medical) risks

Table 6. Statistics of multiple regression coefficients

\begin{tabular}{|c|c|c|c|c|c|c|c|}
\hline \multirow{2}{*}{ Model } & \multicolumn{2}{|c|}{$\begin{array}{l}\text { Unstandardized } \\
\text { Coefficients }\end{array}$} & \multirow{2}{*}{$\begin{array}{l}\text { Standardized } \\
\text { Coefficients } \\
\text { Beta }\end{array}$} & \multirow{2}{*}{$\mathrm{t}$} & \multirow[b]{2}{*}{ ig. } & \multicolumn{2}{|c|}{$\begin{array}{l}95.0 \% \text { Confidence } \\
\text { Interval for B }\end{array}$} \\
\hline & B & Std. Error & & & & $\begin{array}{l}\text { ower } \\
\text { Bound }\end{array}$ & $\begin{array}{l}\text { Upper } \\
\text { Bound }\end{array}$ \\
\hline $\begin{array}{l}\text { q1 How much is your } \\
\text { profession in demand? }\end{array}$ & .195 & .360 & .117 & .543 & 607 & .686 & 1.076 \\
\hline $\begin{array}{l}\text { q2 Competition on the } \\
\text { professional market }\end{array}$ & .575 & .211 & .575 & 2.722 & 035 & 058 & 1.091 \\
\hline $\begin{array}{l}\text { q3 Satisfaction with } \\
\text { organizational culture } \\
\text { and management }\end{array}$ & 1.195 & .360 & .717 & 3.320 & 016 & 314 & 2.076 \\
\hline q4 Feedback & -1.080 & .476 & -.483 & -2.268 & 064 & 2.246 & .085 \\
\hline
\end{tabular}

Insurance companies should consider real medical expenses for treatments and should be focused on better financial coverage for patients, improving the quality of their insurance packages. The state health care system should play a major role and be based on professionals (medical terms) and researchers) opinions.

\section{REFERENCES}

Cheishvili, G. (2016). Universal Healthcare «Black Holes». http://eugeorgia.info/en/article/359/

Getzen, T. (2012). Health Economics and Financing. 5th Edition.

National Health Reports 2001-2017. (2017). Ministry of Labor, Health and Social Affairs of Georgia. https://www.moh.gov.ge/ uploads/files/2019/02.05.19-2012-2017-geo.pdf.

World Health Organization. Health-Care 2017. http://ctc.org.ge/sites/default/files/publications/LG\%20Helth\%20-\%20 CARE\%20-\%202017.pdf.

Reibling, N., Ariaans, M. \& Wendt C. (2019) Worlds of Healthcare: A Healthcare System Typology of OECD Countries Health Policy, 123, 7, 2019, 611-620

Stadhouders, N., Kruse, F., Tanke, M., Koolman, X. \& Jeurissen P, (2019). Effective healthcare cost-containment policies: A systematic review. Health Policy 123(2019)71-79. www.elsevier.com/locate/healthpol.

Verulava T. (2016). Health policy. Ilia State University Publishing House, Tbilisi ISBN 978-9941-18-247-1 http://eprints.iliauni. edu.ge/4643/.

Verulava T. (2015). Healthcare expenditures in line with the recommendations of the World Health Organization and the funding of Georgia's healthcare system. IDFI. Economics and Social Policy. https://idfi.ge/en/health-care-expenditurewho-recommendations-georgia.

Verulava, T. \& Beliskeria, I. (2016). Survey of satisfaction of the beneficiaries of the universal healthcare state program. Health policy and insurance (2). 99-107. ISSN 2449-2469

Verulava, T. \& Jorbenadze, R. (2017). New healthcare system in Georgia: funding with hospitals global budget. Economics and Business (1). 137-143. ISSN 1987-5789 online version. http://eprints.iliauni.edu.ge/6456/2/ekbiz1.pdf 